\title{
DEVELOPMENT OF COMPULSORY MEDICAL INSURANCE IN CONDITIONS OF ECONOMIC UNCERTAINTY
}

\author{
Igor N. Molchanov \\ The Department of Political Economy of Lomonosov Moscow State University; \\ The Financial University under the Government of the Russian Federation, Moscow, Russian Federation

\section{Natalya P. Molchanova} \\ The Financial University under the Government of the Russian Federation, Moscow, Russian Federation
}

\begin{abstract}
The problem of protecting health and increasing the life expectancy of the population is multifaceted and difficult to solve with the existing volumes and dynamics of financial resources allocated by the state for health care and currently accepted budgetary restrictions. In the light of the decision of the priority national goals for the preservation of health, the increase in the life expectancy of the population, the development of human potential, the characteristic features of the Russian system of compulsory medical insurance, the features of its functioning in the current economic conditions require thorough consideration and further development in the prospective period.

The objectives of the work are: to study problems that hamper the implementation of a balanced social policy in the field of compulsory health insurance; substantiation of the need for state regulation of the process of its practical implementation; identification of innovations, the use of which at the present stage of health care reform can have a positive impact on the economic activities of medical organizations; justification of the innovations recommended for use with a view to further development of the organizational and economic mechanism in the field under study.

The work is based on dialectics as a scientific and philosophical method of cognition, laws and categories of economic theory, system approach, analytical and expert economic methods.

The text presents a general vision of the system of compulsory medical insurance: the strategic issues of its development are considered in the post-reform period (1990-2000-ies); the features of its current state (2010th years) are analyzed; the evolution of tactical changes as concrete actions contributing to the attainment of the goals has been studied; some key questions were formulated, which should be focused on the attention of interested parties (subjects of economic relations) in order to develop coordinated management decisions.

Based on the results of the study, conclusions were drawn on the need to improve the organizational and economic foundations of the work of medical and preventive institutions. It is modernization that creates real opportunities for improving the functioning of the mandatory health insurance system. Budgeting for short- and medium-term periods can not take into account the long-term goals of development of medical organizations, this $\infty$ is the contradiction, the uncertainty of their economic activity. In the conditions of overcoming the consequences $\stackrel{\sim}{\sim}$ of the economic recession, it is necessary to intensify actions to strengthen state regulation in the healthcare field, $\therefore$ in conjunction with more intensive use of market instruments.

Key words: social policy, compulsory medical insurance, financial security, compulsory medical insurance fund, health, medical organization.

Citation. Molchanov I.N., Molchanova N.P. Development of Compulsory Medical Insurance in Conditions of Economic Uncertainty. Vestnik Volgogradskogo gosudarstvennogo universiteta. Seriya 3, Ekonomika. Ekologiya [Science Journal of Volgograd State University. Global Economic System], 2018, vol. 20, no. 4, pp. 105-117. (in Russian). DOI: https://doi.org/10.15688/jvolsu3.2018.4.10
\end{abstract}




\title{
РАЗВИТИЕ ОБЯЗАТЕЛЬНОГО МЕДИЦИНСКОГО СТРАХОВАНИЯ В УСЛОВИЯХ ЭКОНОМИЧЕСКОЙ НЕОПРЕДЕЛЕННОСТИ
}

\author{
Игорь Николаевич Молчанов \\ Московский государственный университет им. М.В. Ломоносова; \\ Финансовый университет при Правительстве Российской Федерации, г. Москва, Российская Федерация

\section{Наталья Петровна Молчанова} \\ Финансовый университет при Правительстве Российской Федерации, г. Москва, Российская Федерация
}

Аннотация. Проблема охраны здоровья и увеличения продолжительности жизни населения является многоаспектной и трудно решаемой при существующих объемах и динамике финансовых ресурсов, выделяемых государством на цели здравоохранения и принятых в настоящее время ограничениях в бюджетной сфере. В свете решения приоритетных общегосударственных задач по сохранению здоровья, увеличению продолжительности жизни населения, развитию человеческого потенциала характерные черты российской системы обязательного медицинского страхования, особенности ее функционирования в современных экономических условиях требуют обстоятельного рассмотрения и дальнейшего развития в перспективном периоде.

Целями работы являются: исследование проблем, затрудняющих проведение сбалансированной социальной политики в сфере обязательного медицинского страхования; обоснование необходимости государственного регулирования процесса ее практического осуществления; выявление нововведений, использование которых на современном этапе реформирования здравоохранения может оказать позитивное влияние на экономическую деятельность медицинских организаций; обоснование рекомендуемых для применения нововведений в целях дальнейшего развития организационно-экономического механизма в исследуемой области.

Работа базируется на диалектике как научно-философском методе познания, законах и категориях экономической теории, системном подходе, аналитическом и экспертном экономических методах.

В тексте представлено общее видение системы обязательного медицинского страхования: рассматриваются стратегические вопросы ее развития в пореформенный период (1990-2000-е гг.); проанализированы особенности ее современного состояния (2010-е гг.); исследована эволюция тактических изменений как конкретных действий, способствующих достижению поставленных целей; сформулированы некоторые ключевые вопросы, на изучении которых следовало бы сконцентрировать внимание заинтересованным сторонам (субъектам экономических отношений) в целях выработки согласованных управленческих решений.

По результатам выполненного исследования сделаны выводы о необходимости совершенствования организационно-экономических основ работы лечебно-профилактических учреждений. Именно реформирование создает реальные возможности для улучшения функционирования системы обязательного медицинского страхования. Бюджетирование на кратко- и среднесрочный периоды не может учитывать долгосрочные цели развития медицинских организаций, в этом и есть противоречие, неопределенность их экономической деятельности. В условиях преодоления последствий экономического спада необходима активизация действий по усилению государственного регулирования в сфере здравоохранения в сочетании с более интенсивным использованием рыночных инструментов.

Ключевые слова: социальная политика, обязательное медицинское страхование, финансовое обеспечение, фонд обязательного медицинского страхования, здравоохранение, медицинская организация.

Цитирование. Молчанов И. Н., Молчанова Н. П. Развитие обязательного медицинского страхования в условиях экономической неопределенности // Вестник Волгоградского государственного университета. Серия 3, Экономика. Экология. - 2018. - Т. 20, № 4. - C. 105-117. - DOI: https://doi.org/10.15688/jvolsu3.2018.4.10 


\section{Обязательное медицинское страхование в комплексе мер социальной политики российского государства}

Содержание и проведение социальной политики в условиях экономической неопределенности ${ }^{1}$ является актуальным вопросом и активно изучается учеными и практиками. Исходя из концепции построения социального государства $^{2}$, социальная политика представляет собой совокупность теоретических положений и практических мер, вырабатываемых государственными и негосударственными органами и организациями, направленных на создание условий жизнедеятельности населения на уровне социальных стандартов. Объективная ограниченность различного рода ресурсов обусловливает необходимость совершенствования существующих и выработки новых подходов для соблюдения преемственности в достижении принципа социальной справедливости при предоставлении населению общественных благ и социально значимых услуг. Особенностью современного периода является наличие у экономических субъектов (государства, организаций, населения) заинтересованности в развитии системы государственного социального страхования в направлении достижения большей согласованности их разновекторных интересов и устремлений. Это создает основания для учета различных видов рисков (экономических, социальных, финансовых, инвестиционных и других), способы минимизации которых достаточно специфичны и разнообразны, а достижение паритета возможно только в рамках располагаемой ресурсной базы, на основе ранжирования общественных потребностей.

В Советском Союзе государственная медицина финансировалась за счет бюджетных средств. В начале 1990-х гг. в России началась реализация стратегической задачи по созданию системы обязательного медицинского страхования на основе бюджетно-страховой модели. Однако в этот период государство не располагало необходимыми бюджетными средствами для обеспечения медицинской помощи населению различных возрастных групп на уровне минимальных социальных стандартов, а соответствующие стратегические документы, ориентированные на отраже- ние отраслевых особенностей развития здравоохранения, длительное время не разрабатывались. Были созданы Федеральный фонд обязательного медицинского страхования и территориальные фонды обязательного медицинского страхования (в каждом субъекте Российской Федерации). Постепенно сформировалась нормативная база, включающая регламентируемые государством правовые, экономические и организационные меры в данной области.

Обязательное медицинское страхование является самостоятельным видом социального страхования ${ }^{3}$. Установленные законодательством меры предназначены для того, чтобы при наступлении страхового случая обеспечивать гарантии бесплатного оказания застрахованному лицу медицинской помощи. Данная деятельность осуществляется системой обязательного медицинского страхования за счет собственных средств в пределах территориальной программы, а в определенных законодательством случаях - в рамках базовой программы обязательного медицинского страхования. В течение пореформенного периода функционирования российской экономики предпринимались разнообразные тактические приемы по внедрению принципов страхования в практику работы медицинских организаций, изыскивались возможности привлечения дополнительных финансовых ресурсов в систему здравоохранения в целях предоставления гражданам равных возможностей для получения бесплатных медицинских услуг. Распространение бюджетно-страховой модели в здравоохранении происходило путем введения и последовательного совершенствования порядка взимания страховых взносов и платежей на цели обязательного медицинского страхования.

По мере роста потребностей и развития законодательства постепенно сформировался рекомендуемый перечень источников финансирования здравоохранения. В настоящее время в него включены средства федерального бюджета, бюджетов субъектов Российской Федерации, местных бюджетов; средства обязательного медицинского страхования, средства организаций и граждан; средства, поступившие от юридических и физических лиц, в том числе добровольные пожертвова- 
ния, и иные, не запрещенные российским законодательством источники ${ }^{4}$. Вместе с тем в процессе упорядочения системы обязательного медицинского страхования проявились и обострились некоторые экономические проблемы здравоохранения. «Вследствие дифференциации природно-климатических условий и объективных региональных различий в обеспечении регионов факторами производства, базовые программы территориальных фондов обязательного медицинского страхования во многих субъектах Российской Федерации были дефицитными. По данным государственной статистики, в начале $2010-х$ гг. от 60 до 70 субъектов (при сравнительном анализе за ряд лет) не обеспечивали сбалансированное функционирование бюджетов территориальных фондов» [8, с. 325].

Реформирование деятельности лечебнопрофилактических учреждений значительно улучшило их финансовое положение. В настоящее время основной объем средств концентрируется в государственном внебюджетном Федеральном фонде обязательного медицинского страхования [3, с. 47]. Сведения о совокупных объемах финансирования отрасли из различных разрешенных российским законодательством источников, а также оценочные расчеты по «теневым платежам» содержат- ся в таблице. При проведении расчетов об объемах финансирования по основным источникам поступлений средств в 2017 г. и выполнении прогнозных и оценочных расчетов на 2018 г., наряду с официальными данными Федерального фонда обязательного медицинского страхования и Федеральной службы государственной статистики, по ряду показателей использовались методы экспертных оценок и экстраполяции ${ }^{5}$.

Анализ представленных данных приводит к заключению о недостаточности и неполноте официальной информации о финансировании здравоохранения, что в свою очередь свидетельствует о неопределенности экономической ситуации в изучаемой отрасти. С одной стороны, объемы платных медицинских услуг, дополнительного медицинского страхования, расходов граждан на лекарства, а тем более «теневых» платежей оценивать и прогнозировать достаточно сложно. На их величину влияет множество внешних и внутренних факторов (по отношению не только к системе обязательного медицинского страхования, но и к потребителям медицинских услуг). Например, необходимо четкое определение перечня медицинских услуг, которые могут быть получены гражданами на платной основе. Главный критерий - эти услуги

Финансирование здравоохранения в России, млрд руб.

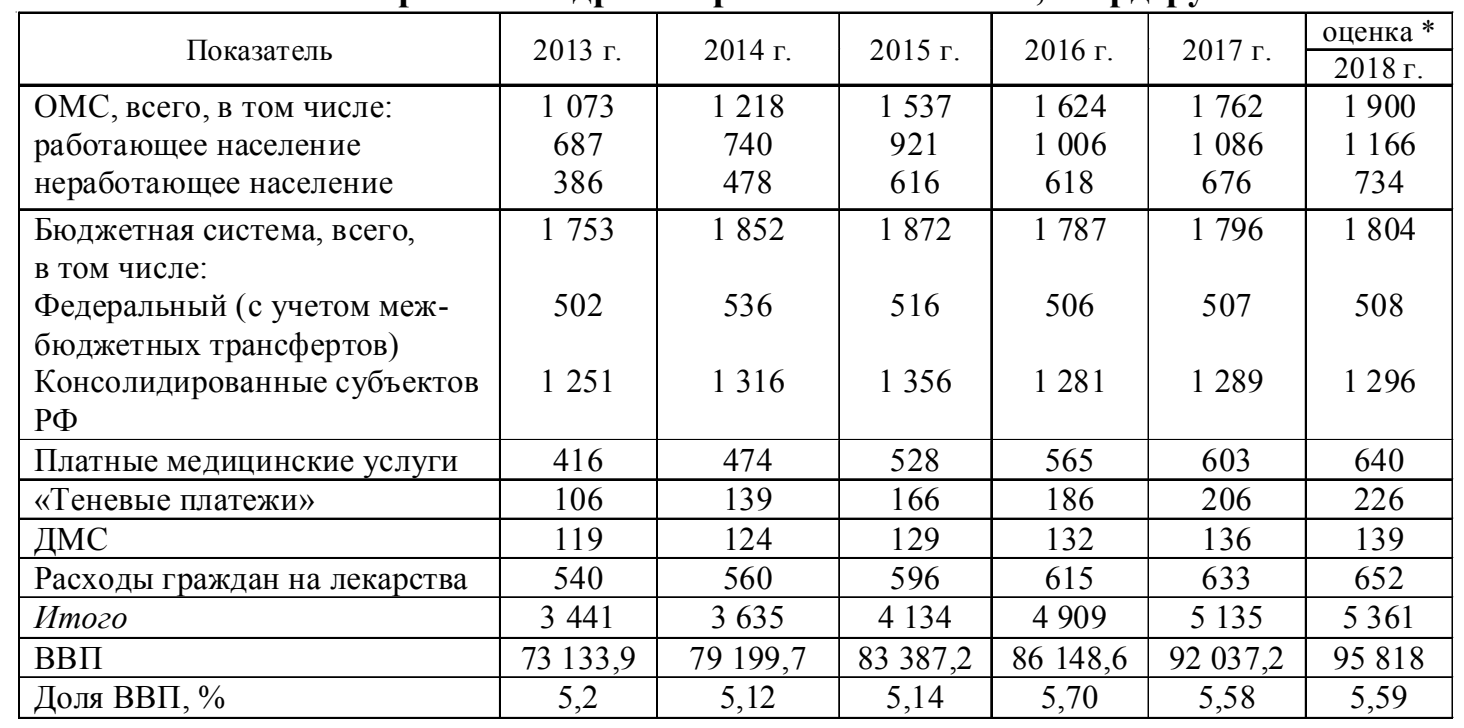

Примечание. Источники информации: 1. Данные за 2009-2015 годы: [1, с. 55]. 2. Данные за 2016 и 2017 гг.: сайт Росстата: http://www.gks.ru/ и оценочные расчеты. 3. Оценочные и прогнозные расчеты на 2018 год (оценка *) выполнены авторами. 
должны превосходить по своему качеству медицинскую помощь, оказываемую в рамках государственных гарантий. Во всех странах с развитым общественным здравоохранением оплата населением части стоимости медицинской помощи является нормой. В России «доля платных медицинских услуг, включая расходы граждан на лекарства, в общих расходах на здравоохранение в 2013-2015 гг. в среднем составляла $30 \% \ldots$, что выше среднемировых показателей (20-25\%)» [1, с. 54]. С другой стороны, отсутствие детерминированности ${ }^{6}$ системы характеризуется различием между необходимым для анализа («идеальным») объемом истинных сведений и их фактическим содержанием. Для информационных потоков, сформированных на основе данных государственной статистики, характерна высокая степень обобщения, что не дает полного представления не только о предлагаемых сегментах и особенностях предоставления медицинских услуг, возможностях их получения в заданных программой государственных гарантий рамках, но и о конечных результатах лечения.

Названные основания подтверждают целесообразность дальнейших исследований в направлении развития методологических основ экономики здравоохранения. Именно учет специфики состояния здоровья пациентов различных половозрастных групп, климатогеографических зон проживания, профессии, уровня образования, а также других факторов должен лежать в основе деятельности по совершенствованию управления отраслью. Данное заключение в полной мере относится и к системе обязательного медицинского страхования, рациональное организационное построение которой в совокупности с достижением безубыточности функционирования лечебнопрофилактических учреждений и страховых медицинских организаций являются ключевыми индикаторами, влияющими на конечные результаты работы российского здравоохранения. Основная проблема состоит в поиске решения задачи эффективного распределения располагаемых ресурсов в целях сохранения здоровья населения в условиях повышения доступности и налаживания контроля качества различных видов предоставляемой медицинской помощи.

\section{Новации современного периода реформирования обязательного медицинского страхования}

Главной составной частью доходов бюджета Федерального фонда обязательного медицинского страхования традиционно выступают страховые взносы на обязательное медицинское страхование. До 2014 г. включительно работодатели уплачивали взносы в Федеральный фонд обязательного медицинского страхования по ставке $5,1 \%$ до достижения суммы заработной платы работника с начала года на уровне 624000 рублей. Суммы, превышающие данный уровень, взносами не облагались. После принятия законодательного решения о снятии ограничений с предельной величины базы для начисления страховых взносов на обязательное медицинское страхование работающего населения, с 2015 г. пороговое значение по заработной плате для взносов в данный Фонд отменено. Благодаря этому страховые взносы за работающее население уплачиваются плательщиками со всех сумм выплат и иных вознаграждений, предназначенных физическим лицам, по ставке 5,1\% (то есть от всей начисленной за календарный год заработной платы работников) $[5$, с. 91]. Исключение составляют средства, не подлежащие обложению страховыми взносами. Следовательно, не только объем, но и удельный вес страховых взносов, доля которых является преобладающей в общих доходах Фонда, будет постепенно увеличиваться (при условии роста оплаты труда работающего населения) ${ }^{7}$. В 2019 г. планируется повысить тариф страховых взносов до $5,9 \%{ }^{8}$ для всех категорий плательщиков, что будет способствовать дальнейшему росту поступлений и наполнению Фонда финансовыми ресурсами. Безусловно, реализация данного решения существенно улучшит финансовое положение обязательного медицинского страхования и, соответственно, финансирование предоставления медицинских услуг.

Произошли изменения в процедуре начисления страховых взносов на обязательное медицинское страхование неработающего населения в территориальные фонды обязательного медицинского страхования. Если ранее данные средства передавались из бюджетов 
субъектов Российской Федерации напрямую в территориальные фонды, то с 2012 г. они первоначально поступают в бюджет Федерального фонда, а затем в составе субвенций направляются в бюджеты территориальных фондов. Расчет объема поступлений страховых взносов на обязательное медицинское страхование неработающего населения производится исходя из численности неработающих застрахованных лиц в субъектах Российской Федерации (на 1 апреля года, предшествующего планируемому) и соответствующего тарифа страхового взноса ${ }^{9}$. Таким образом, развитие законодательной базы сопровождается введением весьма продуктивных новшеств.

Порядок уплаты страховых взносов на обязательное медицинское страхование предусматривает замещение существовавшей ранее практики ассигнований на данные цели из бюджетов субъектов Российской Федерации средствами Федерального фонда обязательного медицинского страхования, которые образуются за счет поступления средств из разных источников. Новацией является четкое разделение различных видов медицинской помощи по источникам финансирования. Так, оплата медицинской помощи из перечня услуг, включенных в базовую программу обязательного медицинского страхования, производится из средств Федерального фонда обязательного медицинского страхования. За счет бюджетных средств выполняется оплата, вопервых, медицинской помощи, не входящей в базовую программу обязательного медицинского страхования; во-вторых, расходов, не включенных в тариф на оплату медицинской помощи; в-третьих, расходов на лекарственное обеспечение отдельных категорий граждан; в-четвертых, некоторых медицинских услуг (например, медицинские осмотры призывников, медицинское освидетельствование и др.). В целом принятые меры организационного и экономического характера направлены не только на улучшение упорядоченности и управляемости системы здравоохранения, но и на повышение результативности работы системы обязательного медицинского страхования в условиях экономической неопределенности.

Произошедшие нововведения закреплены в законодательстве, и их обоснование было выполнено при разработке и рассмотрении законопроектов в Государственной думе Федерального собрания Российской Федерации; они распространяются на формирование средств Федерального фонда обязательного медицинского страхования и объективно корреспондируются с изменениями в методологии и практике финансового планирования. Важно отметить, что применение принципа подушевого финансирования позволило уже в первые годы реформирования существенно снизить различия в размерах доходов территориальных фондов обязательного медицинского страхования в расчете на одного жителя при одновременном существенном росте объема предоставляемых субвенций. Согласно официальным комментариям Председателя Федерального фонда обязательного медицинского страхования Н.Н. Стадченко, «размер субвенции увеличился с 2012 по 2017 г. с 640 млрд руб. до 1,5 трлн руб., или в 2,4 раза. Подушевой норматив за счет средств обязательного медицинского страхования, за тот же период, возрос с 4 102,9 руб. до 8896 руб., или в 2,2 раза» [9, с. 6]. В результате предпринятых действий в настоящее время существенных отклонений между отдельными территориями по названным показателям не наблюдается, а мероприятия базовой программы обязательного медицинского страхования в территориальном разрезе практически полностью обеспечены финансовыми ресурсами. Таким образом, происходящие изменения объективно направлены на снижение экономической неопределенности, что проявляется, с одной стороны, в налаживании самоорганизации и стабильности функционирования системы здравоохранения, а с другой - в повышении управляемости работой медицинских организаций.

Федеральный фонд обязательного медицинского страхования выступает в качестве финансового центра, который концентрирует средства из различных источников. «Основной целью перехода на одноканальное финансирование здравоохранения считается консолидация финансовых ресурсов в системе обязательного медицинского страхования, финансирование за фактически оказанные услуги, то есть по принципу, когда “деньги следуют за пациентом”» [6, с. 61]. По своей сути одно- 
канальное финансирование позволяет консолидировать финансовые средства в едином пуле и, таким образом, поддерживать нормальное (безубыточное) функционирование медицинских организаций как первичного звена национальной системы здравоохранения.

В итоге финансовые ресурсы системы обязательного медицинского страхования предстают в агрегированной форме, поскольку в процессе объединения из различных источников денежные средства абстрагируются от конкретных отправителей, концентрируются в едином финансовом центре ${ }^{10}$, а затем в процессе адресного распределения проходят ряд стадий и поступают конкретным получателям. Их использование априори направлено на достижение конечного результата, существо которого сформулировано в материалах Всемирной организации здравоохранения (BO3) и выражается следующим логическим построением: «Справедливость - Отзывчивость - Хорошее здоровье». Данный ориентир в развитии экономических отношений системы здравоохранения направлен на обеспечение максимально возможного (наивысшего) уровня здоровья, а его практическое достижение возможно только на основе задействования всех располагаемых ресурсов $[10]^{11}$. Как представляется, для реализации приведенной выше формулировки отвлечения средств из каких-то иных источников не требуется: важно наладить консолидацию всех разрешенных законодательством финансовых ресурсов (доходов, поступлений, накоплений) и обеспечить их результативное применение в практике работы лечебно-профилактических учреждений.

\section{Возможные направления}

\section{дальнейших исследований экономики}

\section{здравоохранения в контексте развития} обязательного медицинского страхования

Для принятого на законодательном уровне порядка организации обязательного медицинского страхования характерно поэтапное внедрение новшеств с апробацией рекомендуемых методов и инструментов на практике. Установка на использование системного подхода содержится в базовом законе о стратегическом планировании ${ }^{12}$, согласно которо- му перспективное развитие не только всей страны, но и отдельных отраслей и территорий регламентируется совокупностью прогнозно-плановых документов, разрабатываемых на различных уровнях управления. Применительно к федеральному уровню, в их состав в качестве основных входят: долгосрочный прогноз, стратегия социально-экономического развития, государственные и целевые программы, финансовые планы различной продолжительности. Данный порядок применяется в отраслевом и территориальном разрезах, в том числе в управлении здравоохранением и системой обязательного медицинского страхования. Однако, несмотря на стремление к согласованной работе всех заинтересованных участников экономических отношений, всего общества, до настоящего времени не завершено создание целостного комплекса инструментов, опосредующих деятельность по управлению развитием здравоохранения в долгосрочном и среднесрочном периодах.

Наряду с финансированием через систему обязательного медицинского страхования, для повышения финансового обеспечения медицинских организаций используется привлечение бюджетных средств. Поддержка из федерального бюджета на практике исполняется посредством разработки государственных и целевых федеральных программ. Примером может служить Государственная федеральная программа «Развитие здравоохранения», реализация которой первоначально рассчитывалась на период с 2013 по 2020 год ${ }^{13}$. В ней установлены цели, задачи, основные направления развития отрасли и ключевые проекты, а также механизмы их реализации и финансовое обеспечение. По состоянию на конец 2017 г. целый ряд подпрограмм и мероприятий данной Программы были успешно выполнены.

Вместе с тем ряд внешнеэкономических факторов инициировали изменения в бюджетной политике, что в конечном счете привело к новациям в программно-целевом планировании и переводу данной Программы на проектное управление ${ }^{14}$. На основе сформулированных в ней приоритетных целей (увеличение ожидаемой продолжительности жизни при рождении, снижение смертности по различным причинам, повышение удовлетворенности на- 
селения качеством медицинской помощи) Министерством здравоохранения Российской Федерации планируется организация экономической работы в отрасли на перспективный период, определяются объемы финансирования и контроль за исполнением сформированных подпрограмм и проектных мероприятий. Программа, как нормативный документ, имеет стратегический уклон и является основой для проведения целенаправленных действий по модернизации работы как отрасли в целом, так и медицинских организаций. Однако объективно существующие различия в природно-климатических условиях, располагаемом совокупном экономическом потенциале, инфраструктурном обеспечении российских регионов объективно влияют на доступность медицинских услуг, что обусловливает необходимость учета специфики территорий и, соответственно, ее отражения в законодательных положениях, нормативных документах и научных концепциях социально-экономического развития субъектов Российской Федерации. Также требуют корректировки в региональном разрезе рекомендуемые наукой и практикой инструменты государственного регулирования применительно к рассматриваемой области исследования.

В условиях экономической неопределенности достаточно сложно прогнозировать развитие объекта управления в будущем и, следовательно, выстраивать долгосрочные планы стратегического характера. Работу над совершенствованием принятой в России модели организации обязательного медицинского страхования целесообразно выстраивать в сопряжении с концептуальным программным документом - проектом Стратегии развития здравоохранения на период до 2025 года ${ }^{15}$. Однако в предлагаемом варианте Стратегии акцентируется внимание только на приоритетных направлениях здравоохранения, но не содержится мер по их ресурсному обоснованию и финансовому обеспечению, не акцентируется внимание на вопросах дальнейшего развития обязательного медицинского страхования. В частности, предусматривается: обеспечение доступности медицинской помощи населению; разработка и внедрение новых медицинских и информационных технологий; формирование ответственного отношения граж- дан, особенно трудоспособного возраста, к своему здоровью; развитие центров экспорта высокотехнологичных медицинских услуг; цифровизация здравоохранения; непрерывное повышение уровня квалификации медицинских работников; развитие инфраструктуры здравоохранения с использованием механизмов государственно-частного партнерства и инвестиционных договоров.

Как представляется, данный перечень можно рассматривать в качестве долгосрочного общего плана развития отрасли. Однако с точки зрения методологического сопровождения проект Стратегии нуждается в доработке и корректировке отдельных положений в связи с динамично изменяющимися внутренними и внешними обстоятельствами, влияющими на условия функционирования субъектов хозяйствования, а именно внедрением: единой государственной информационной системы в сфере здравоохранения с комплексной аналитической программой обработки больших массивов информации; информационных систем поддержки принятия врачебных решений, в том числе с использованием технологий искусственного интеллекта (машинного обучения); персонифицированного учета фактических затрат лекарственных средств, медицинских изделий и расходных материалов в условиях стационаров. На наш взгляд, требует внимания обоснование финансирования материально-технического обеспечения всего комплекса предполагаемых для реализации мер, предусматриваемых в проекте Стратегии.

Передача администрирования собираемости страховых взносов Федеральной налоговой службе с 1 января 2017 г. ${ }^{16}$ позволила повысить объем поступлений за счет укрепления платежной дисциплины и внесения изменений в технологию и логистику работы системы обязательного медицинского страхования. По экспертным оценкам, придание Федеральной налоговой службе новых функций позволяет увеличить собираемость страховых взносов на обязательное медицинское страхование занятого населения и сбалансировать бюджет Федерального фонда обязательного медицинского страхования в текущем и среднесрочном периодах. Как представляется, в целях повышения результативности 
работы объединение средств в бюджетах фондов обязательного медицинского страхования для финансового обеспечения учреждений здравоохранения «должно сопровождаться организацией систем контроля и мониторинга за их использованием» [7, с. 78].

Некоторые российские регионы имеют опыт по организации работы координационных структур, которые консолидируют финансовые ресурсы, поступающие из нескольких источников (страховых взносов на обязательное медицинское страхование, частных средств юридических и физических лиц и др.). Например, в Томской области в начале 1990-х гг. было создано Организационно-аналитическое бюро, в задачи которого входила «разработка системы финансирования медицинских организаций в соответствии с достигнутыми результатами» [4, с. 11]. Это открывает новые возможности для развития финансовых отношений, поскольку при подобном объединении средства теряют принадлежность к источнику и доводятся до медицинской организации единым финансово связанным агрегатом, а их расходование осуществляется не в соответствии с исходными параметрами (например, целевым назначением тарифа), а согласно достигнутому результату оказанных медицинских услуг. В этой связи необходимо соблюдение равновесия между численностью населения, которое пользуется услугами обязательного медицинского страхования (согласно их общедоступному набору), и сформированным за счет различных источников объемом финансовых ресурсов, предназначенных для нужд функционирования и развития отрасли «Здравоохранение». Для повышения результативности работы при переходе на одноканальное финансирование целесообразно объединять законодательно разрешенные средства в общий финансовый пул. Одним из вариантов для обслуживания лечебно-профилактических учреждений может стать создание в административных центрах субъектов Российской Федерации специальных организационных структур на основе многофункциональных медицинских информационно-аналитических центров.

Ознакомление с накопленным опытом реформирования рынка медицинского страхования в США приводит к выводу о том, что «основную роль в обеспечении эффективности национальной системы здравоохранения играет государство как через выбор способа финансирования (страховой или бюджетный), так и через контроль цен на медицинскую помощь» [2, с. 38]. По данному вопросу, как и в целом по степени участия государства в решении социальных проблем, у исследователей нет единой точки зрения. Некоторые ученые (Дэвид Ромер, Роберт Лукас и др.) рассматривают государственные расходы на социальные цели, как обременительные. Вместе с тем широкую известность приобрели макроэкономические модели Джона Мейнарда Кейнса и его последователей о благотворном влиянии государственных инвестиций на экономический рост. Глубоко исследованы возможности варьирования объемами государственных расходов и ставками налогов в зависимости от стадии экономического цикла и др. Естественно, при реализации крупномасштабных экономических проектов нужно учитывать состояние экономики, влияние всей совокупности разнообразных факторов, и эту задачу в каждом конкретном случае призваны решать совместно ученые и практики. В рамках данного направления ключевая роль принадлежит изысканию возможностей для роста совокупной производительности факторов производства (труда, земли, капитала, предпринимательских способностей). Следовательно, приоритетное внимание рекомендуется направить на поддержку инвестиционного спроса, в том числе в общественно значимые инвестиционные проекты, а также на стимулирование трудовой активности населения, в основе которой - качество человеческого капитала, базирующееся на стремлении к непрерывному повышению уровня образования и квалификационных требований работников ${ }^{17}$.

При разработке мер по обеспечению проводимой политики средствами бюджетного воздействия следует продумывать разнообразные тактические приемы, которые в конечном итоге будут способствовать увеличению государственных расходов на здравоохранение. Согласно результатам исследования O. Barbiero и В. Cournede, выполненного в начале 2010-х гг., существует обратно пропорциональная связь между объемами финансовых вложений в охрану здоровья и уровнями 
заболеваемости (смертности) населения. Например, одним из результатов роста государственных расходов становится улучшение динамики названных демографических показателей, что в долгосрочном периоде проявляется в увеличении продолжительности жизни [12]. В составе значимых компонентов, определяющих экономическое положение страны, исследователи A. Afonso и T. Jalles отмечают увеличение численности рабочей силы и повышение качества человеческого капитала. Вместе с тем они констатируют негативные последствия от увеличения непроизводительных расходов: например, делают выводы об отрицательном влиянии на динамику экономического роста увеличивающегося государственного потребления, либо возрастающего фонда оплаты труда в государственном сектоpe [11]. В связи с этим следует положительно оценить предпринимаемые Правительством России усилия по снижению затрат на содержание управленческого аппарата, в том числе и в сфере здравоохранения ${ }^{18}$.

\section{Заключение}

Основой дальнейшей работы, направленной на совершенствование организационноэкономического механизма в сфере обязательного медицинского страхования, является активизация научных исследований по развитию теоретических и методологических основ экономики и управления здравоохранением. Ввиду сложности и дискуссионности рассматриваемых вопросов ключевое значение приобретают междисциплинарные работы. Необходимо наличие согласованного всеми заинтересованными сторонами концептуального документа программного характе$\mathrm{pa}$ - одобренной и утвержденной Стратегии развития здравоохранения, один из разделов которой должен быть посвящен проблемам обязательного медицинского страхования. Дискуссионные методологические вопросы могут быть частично разрешены посредством заимствования практики организации данной работы в странах ОЭСР. Различные подходы к реформированию здравоохранения, применяющиеся за рубежом, требуют внимательного изучения и апробации в российских условиях (см., например, [13]).
В период становления в России социального государства переход на страховую модель представляется весьма спорным, поскольку бюджетные средства традиционно играют весомую роль в финансировании здравоохранения в различных зарубежных странах. В этой связи приоритетное внимание целесообразно было бы уделить ресурсному обоснованию мероприятий стратегического характера, обновлению методологических основ и методического аппарата (положений, рекомендаций, стандартов и инструкций), а также стратегическим и тактическим вопросам прогнозирования и планирования экономической деятельности организаций здравоохранения.

Несмотря на объективные трудности современного периода экономического развития, обязательному медицинскому страхованию по праву принадлежит лидирующее место в системе социальной защиты населения. Существует потребность в развитии различных форм и методов экономического и финансового регулирования, которые следовало бы положить в основу модернизации деятельности организаций здравоохранения. На состояние здоровья населения оказывают влияние разнообразные факторы, находящиеся за границами сформировавшихся финансовых отношений в отрасли. Поэтому ключевая роль в разрешении существующих противоречий между объемом финансовых ресурсов, выделяемых государством на нужды здравоохранения и потребностями населения в медицинских услугах, закономерно принадлежит поиску путей обеспечения экономического роста, развития материально-технической базы производства. Результатом целенаправленной экономической политики становится рост производимого ВВП, валовой добавленной стоимости и других макроэкономических показателей, что закономерно отражается на расширении базы для сбора налогов и тарифных платежей. В процессе дальнейших преобразований первоочередное внимание предстоит уделить поиску таких вариантов налогообложения и страховых взносов хозяйствующих субъектов, которые позволили бы существенно увеличить объем финансовых ресурсов, консолидируемых для обеспечения экономической деятельности организаций здравоохране- 
ния. Особое внимание в научных исследованиях предстоит сконцентрировать на развитии теоретических положений, разработке методических и практических рекомендаций, совершенствовании хозяйственного механизма в социальной сфере для обеспечения устойчивой работы лечебно-профилактических учреждений различных организационно-правовых форм в рыночных условиях.

\section{ПРИМЕЧАНИЯ}

1 Неопределенность организационно-экономической системы традиционно рассматривается в нескольких аспектах: как мера информации и ее качество; как отсутствие детерминированности системы; как возможность выбора альтернатив будущего развития; как атрибутивный источник риска; как неоднозначность реализации событий; как естественный ограничитель управляемости и стабильности системы.

${ }^{2}$ Согласно ст. 7 Конституции Российской Федерации, Российская Федерация - социальное государство, политика которого направлена на создание условий, обеспечивающих достойную жизнь и свободное развитие человека.

${ }^{3}$ Статья 3 Федерального закона от 29.11.2010 № 326-Ф3 «Об обязательном медицинском страховании в Российской Федерации» (с изм. и доп.). Доступ из справ.-правововой системы «Гарант» (http://base.garant.ru/12180688/).

4 Статья 82 Федерального закона от 21.11.2011 № 323-Ф3 «Об основах охраны здоровья граждан в Российской Федерации» (с изм. и доп.). Доступ из справ. правововой системы «Гарант» (http://base.garant.ru/12191967/).

5 Экстраполяция является признанным методом прогнозирования на краткосрочный период. Как известно, вероятность исполнения самого надежного прогноза может составить от 50 до $60 \%$.

6 Детерминированность (в переводе с лат. «определяемость») - сложная научная категория, которая рассматривается в философии, психологии, праве и является антонимом стохастичности. Детерминированность подразумевает однозначную предопределенность, при которой у каждого следствия есть строго определенная причина. Применительно к здравоохранению для потребителей медицинских услуг характерна целевая (нацеленная на будущее) детерминация, которая определяет поведение субъекта в настоящем. Однако при этом возникают различные ограничения (например, по доступности услуг), которые определяются различными факторами.
7 Данную тенденцию можно проследить при анализе официальных статистических материалов и данных Федерального фонда обязательного медицинского страхования. Например, в 2016 г. доля средств обязательного медицинского страхования в общих объемах соответствующего Федерального фонда равнялась $98 \%$ [9].

${ }^{8}$ Статья 427 Налогового кодекса Российской Федерации (ч. 2) от 05.082000 № 117-Ф3. URL: http://www.consultant.ru/document/cons_doc_LAW 28165/

9 Федеральный закон от 30.11.2011 № 354-Ф3 «О размере и порядке расчета тарифа страхового взноса на обязательное медицинское страхование неработающего населения» (с изм. и доп.). Доступ из справ. правововой системы «Гарант» (http:// base.garant.ru/12192464/).

10 Здесь имеется в виду необходимость создания условий для консолидации финансовых ресурсов из разных источников в одной организации; это может быть фонд; финансовый центр и т. д. По мнению некоторых исследователей, есть различные варианты трансформации деятельности фондов обязательного медицинского страхования, которые могут быть реализованы в перспективе, в зависимости от развития общей экономической ситуации в стране (см., например, [6]).

11 Согласно определению ВОЗ, «здоровье»это состояние полного физического, душевного и социального благополучия, а не только отсутствие болезней или физических дефектов.

12 Федеральный закон от 28 июня 2014 г. № 172-Ф3 «О стратегическом планировании в Российской Федерации» (с изм. и доп.). Доступ из справ.-правововой системы «Гарант» (http://base. garant.ru/12192464/).

13 Государственная программа Российской Федерации «Развитие здравоохранения» : утв. Постановлением Правительства Российской Федерации от 15.04.2014 № 294. URL: https://programms.gov.ru/

14 Постановление Правительства Российской Федерации от 26 декабря 2017 г. № 1640 «Об утверждении государственной программы Российской Федерации «Развитие здравоохранения» на период 2018 2025 годы. URL: https://government.ru/docs/30817/

15 Официальный сайт Министерства здравоохранения Российской Федерации. URL: https: //www.rosminzdrav.ru/ministry/61/22/stranitsa-979/ strategiya-razvitiya-zdravoohraneniya-rossiyskoyfederatsii.

16 Федеральный закон от 03.07.2016 № 243-Ф3 «О внесении изменений в части первую и вторую Налогового кодекса Российской Федерации в связи с передачей налоговым органам полномочий по администрированию страховых взносов на обязательное пенсионное, социальное и медицинское 
страхование» (с изм. и доп.). Доступ из справ.-правововой системы «Гарант» (http://base.garant.ru/ 71434214/).

17 Как известно, экономика любого государства испытывает острую потребность в инвестициях, и наша страна не является исключением. А уж на какие цели их направить - это должно решать Правительство (с учетом мнений экспертов и общественности; ведь сейчас приоритетное внимание уделяется формированию и обновлению состава общественных экспертных советов при законодательных и исполнительных органах власти).

${ }^{18}$ Сокращение аппарата управления вызвано различными причинами, в том числе и цифровизацией экономики. Этот объективный процесс сопровождается уменьшением расходов на оплату труда административно-управленческого персонала, что является весьма позитивной, положительной тенденцией.

\section{СПИСОК ЛИТЕРАТУРЫ}

1. Архипов, А. П. Будущее медицинского страхования в России: больше ясности не становится / А. П. Архипов // Финансы. - 2016. - № 11. C. 54-59.

2. Архипов, А. П. Можно ли обойтись без единой системы обязательного медицинского страхования? Некоторые уроки реформы рынка медицинского страхования в США / А. П. Архипов // Финансы. - 2018. - № 1. - С. 34-38.

3. Белоусова, Т. А. Проблемы медицинского страхования в России: что подсказывает опыт стран ОЭСР / Т. А. Белоусова // Финансы. - 2017. -№ 10. C. $46-51$.

4. Гринкевич, Л. С. Одноканальное финансирование: из прошлого в будущее здравоохранения России / Л. С. Гринкевич, С. А. Банин // Финансы и кредит. - 2016. - № 33 (2016). - С. 2-20.

5. Гура, Г. М. Обязательное медицинское страхование: возможности и перспективы / Г. М. Гуpa // Территория науки. - 2014. - № 6. - С. 88-94.

6. Дементьев, Д. В. К вопросу о финансировании медицинских учреждений / Д. В. Дементьев // Финансы. - 2016. - № 11. - С. 60-64.

7. Молчанов, И. Н. Инновационные подходы в развитии здравоохранения / И. Н. Молчанов // Экономический форум «Экономика в меняющемся мире» : сб. науч. ст. (24-28 апр. 2017 г.). - Казань : Изд-во Казан. ун-та, 2017. - С. 78-80.

8. Молчанов, И. Н. Трансформация здравоохранения как социально-экономического института в новых экономических условиях: финансовый аспект / И. Н. Молчанов, Н. П. Молчанова // Проблемы конфигурации глобальной экономики века: идея соци- ально-экономического прогресса и возможные интерпретации : сб. науч. ст. Том первый / под ред. М. Л. Альпидовской, С. А. Толкачева. - Краснодар, 2018. - С. 323-331.

9. Стадченко, Н. Н. Приоритетом базовой программы ОМС остается финансовое обеспечение первичной медико-санитарной помощи / Н. Н. Стадченко // Обязательное медицинское страхование в Российской Федерации. - 2017. - № 5. C. 6-7.

10. Стратегическое руководство в интересах здоровья в XXI веке. - Копенгаген : Европейское региональное бюро ВОЗ, 2011. - 134 с.

11. Afonso, A. Fiscal composition and long-term growth / A. Afonso, T. Jalles // ECB Working Paper Series, № 1518. - Frankfurt am Main : European Central Bank, 2013. - 45 p. - Electronic text data. - Mode of access: https://www.ecb.europa.eu/pub/pdf/scpwps/ ecbwp1518.pdf?4742f76f5972a1a3e43b34e8fd9a9595. Title from screen.

12. Barbiero, O. New econometric estimates of long-term growth effects of different areas of public spending / O. Barbiero, B. Cournede // OECD Economics Department Working Papers. - 2013. № 1100 .

13. Getting Health Reform Right / by Marc J. Roberts, William Hsiao, Peter Berman, Michael R. Reich. - Oxford University Press, 2002 (October).

\section{REFERENCES}

1. Arkhipov A.P. Budushchee meditsinskogo strakhovaniya $v$ Rossii: bolshe yasnosti ne stanovitsya [The future of medical insurance in Russia: more clarity does not become]. Finansy [Finances], 2016, no. 11, pp. 54-59.

2. Arkhipov A.P. Mozhno li oboytis bez edinoy sistemy obiazatelnogo meditsinskogo strakhovaniya? Nekotorye uroki reformy rynka meditsinskogo strakhovaniya $\mathrm{v}$ SShA [Is it possible to do without a single system of compulsory health insurance? Some Lessons of the Reform of the Medical Insurance Market in the US]. Finansy [Finances], 2018, no. 1, pp. 34-38.

3. Belousova T.A. Problemy meditsinskogo strakhovaniya v Rossii: chto podskazyvaet opyt stran OESR [Problems of health insurance in Russia: what does the experience of OECD countries suggest?]. Finansy [Finances], 2017, no. 10, pp. 46-51.

4. Grinkevich L.S., Banin S.A. Odnokanalnoe finansirovanie: iz proshlogo $\mathrm{v}$ budushchee zdravookhraneniya Rossii [Single-channel financing: from the past to the future of Russia's health]. Finance and credit, 2016, no. 33 (2016), pp. 2-20.

5. Gura G.M. Obiazatelnoe meditsinskoe strakhovanie: vozmozhnosti i perspektivy [Obligatory 
medical insurance: opportunities and prospects]. The territory of science, 2014, no. 6, pp. 88-94.

6. Dementev D.V. K voprosu o finansirovanii meditsinskikh uchrezhdeniy [To the question of financing medical institutions]. Finansy [Finances], 2016, no. 11, pp. 60-64.

7. Molchanov I.N. Innovatsionnye podkhody $\mathrm{v}$ razvitii zdravookhraneniya [Innovative approaches in the development of health]. Ekonomicheskiy forum "Ekonomika v menyayushchemsya mire»: sb. nauch. st. (24-28 aprelya 2017 g.) [Economic Forum "Economics in a Changing World": Sat. scientific articles (April 24-28, 2017)]. Kazan, Izd-vo Kazan. unta, 2017, pp. 78-80.

8. Molchanov I.N., Molchanova N.P. Transformatsiya zdravookhraneniya kak sotsialnoekonomicheskogo instituta v novykh ekonomicheskikh usloviyakh: finansovyy aspekt [Transformation of health care as a socio-economic institution in the new economic conditions: the financial aspect]. Alpidovskaya M.L., Tolkachev S.A., eds. Problemy konfiguratsii globalnoy ekonomiki veka: ideya sotsialno-ekonomicheskogo progressa $i$ vozmozhnye interpretatsii: sb. nauch. st. Tom pervyi. Krasnodar, 2018, pp. 323-331.

9. Stadchenko N.N. Prioritetom bazovoy programmy OMS ostaetsya finansovoe obespechenie pervichnoy mediko-sanitarnoy pomoshchi [Priority of the basic program of $\mathrm{CHI}$ remains the financial provision of primary health care]. Mandatory medical insurance in the Russian Federation, 2017, no. 5, pp. 6-7. (in Russian).

10. Strategicheskoe rukovodstvo $v$ interesakh zdorovya $v$ XXI veke. Copenhagen, WHO Regional Office for Europe, 2011. 134 p.

11. Afonso A., Jalles T. Fiscal composition and long-term growth. ECB Working Paper Series, No. 1518. Frankfurt am Main, European Central Bank, 2013. 45 p. URL: https://www.ecb.europa.eu/pub/pdf/scpwps/ ecbwp1518. pdf?4742f76f5972a1a 3e43b34 e8fd9a9595.

12. Barbiero O., Cournede B. New Econometric Estimates of Long-term Growth Effects of Different Areas of Public Spending. OECD Economics Department Working Papers, 2013, no. 1100.

13. By Marc J. Roberts, William Hsiao, Peter Berman, Michael R. Reich. Getting Health Reform Right. Oxford University Press, 2002 (October).

\section{Information about the Authors}

Igor N. Molchanov, Doctor of Economic Sciences, Professor of the Department of Political Economy of Lomonosov Moscow State University, Leninskie gory, 1, 119991 Moscow, Russian Federation; Professor of the Department of Public Finance of the Financial University under the Government of the Russian Federation, Leningradsky Prosp., 49, 101000 Moscow, Russian Federation, inmolchanov@fa.ru, https://orcid.org/0000-0003-4252-2387

Natalya P. Molchanova, Doctor of Economic Sciences, Associate Professor, Professor of the Department of Public Finance of the Financial University under the Government of the Russian Federation, Leningradsky Prosp., 49, 101000 Moscow, Russian Federation, npmolchanova@fa.ru, https://orcid.org/ 0000-0002-3019-0672

\section{Информация об авторах}

Игорь Николаевич Молчанов, доктор экономических наук, профессор кафедры политической экономии, Московский государственный университет им. М.В. Ломоносова, Ленинские горы, 1, 119991 г. Москва, Российская Федерация; профессор департамента общественных финансов, Финансовый университет при Правительстве Российской Федерации, просп. Ленинградский, 49, 101000 г. Москва, Российская Федерация, inmolchanov@fa.ru, https://orcid.org/0000-0003$4252-2387$

Наталья Петровна Молчанова, доктор экономических наук, доцент, профессор департамента общественных финансов, Финансовый университет при Правительстве Российской Федерации, просп. Ленинградский, 49, 101000 г. Москва, Российская Федерация, npmolchanova@fa.ru, https://orcid.org/0000-0002-3019-0672 